FedUni ResearchOnline

http://researchonline.federation.edu.au

This is the peer-reviewed version of the following article:

Saadat, M., Hasanzade, A., Khandelwal, M. (2015) Differential evolution algorithm for predicting blast induced ground vibrations. International Journal of Rock Mechanics and Mining Sciences, 77, 97-104.

Which has been published in final form at:

http://doi.org/10.1016/j.jjrmms.2015.03.020

Copyright (c) 2015 Elsevier Ltd. This manuscript version is made available under the CC-

BY-NC-ND 4.0 license http://creativecommons.org/licenses/by-nc-nd/4.0/ 
IJRMMS-D-14-00434 - edited and approved by editor

Technical Note

\title{
Differential Evolution Algorithm for Predicting Blast Induced Ground Vibrations
}

\author{
Mahdi Saadat $^{1}$, Ali Hasanzade ${ }^{2}$, Manoj Khandelwal ${ }^{3}$ \\ ${ }^{1}$ Rock Mechanics Group, Mining Engineering Department, Faculty of \\ Engineering, ShahidBahonar University of Kerman, P.O. Box 76175-133, Kerman, \\ Iran \\ ${ }^{2}$ Control Engineering Group, Electrical Engineering Department, Faculty of \\ Engineering, ShahidBahonar University of Kerman, P.O. Box 76175-133, Kerman, \\ Iran \\ ${ }^{3}$ Faculty of Science and Technology, Federation University Australia, PO Box \\ 663, Ballarat, Victoria 3353, Australia \\ * corresponding author \\ Phone: +6135327 9821 \\ Email: m.khandelwal@ federation.edu.au
}




\section{Introduction}

One of the most crucial problems in construction blasting is to predict and then mitigate ground vibration [1]. Blast induced ground vibration is considered as one of the most important environmental hazards of mining operations and civil engineering projects. Intense vibration can cause critical damage to structures and plants nearby the open-pit mines, dams, and mine slopes, etc. [2-3]. Researchers who deal with this undesirable phenomenon take into account various range of parameters in order to mitigate the detrimental effects of blasting. Blast-influencing parameters can be divided into two categories [2]: uncontrollable parameters, such as geological and geotechnical characteristics of the rockmass, and controllable parameters, such as burden, spacing, stemming, sub-drilling, delay time, etc.

A number of researchers have worked in this area and have considered different combination of aforementioned parameters topredict the Peak Particle Velocity (PPV). This specific parameter has been widely used in practice to forecast and evaluate blast damages of structures [2]. The conventional PPV models suggested by various researchers [4-7] are mostly based on the amount of explosive charge per delay and distance from blast face to monitoring point.Theymade their effort to take into consideration more influential parameters to propose empirical models. These days, researchers are using variety of contemporary function approximation methods, i.e. artificial neural network (ANN), support vector machine (SVM), adaptive neuro-fuzzy inference system (ANFIS), genetic algorithm (GA), etc, to predict the blast induced ground vibration [8-16].

Other approaches,like numerical, empirical, etc models are also being used by various researchers to evaluate the adverse effect of blasting. Ghasemi et al. [17] used dimensional analysis (DA) technique and montecarlo(MC) method to predict the effects of controllable blasting parameters on flyrock distance in the Sungun copper mine, Iran. In their study,burden, spacing, stemming, blasthole length,blasthole diameter, powder factor, and mean charge per blastholewere used as major controllable blasting parameters to constitute stochastic model.

Babanouri et al. [18] used 'linear superposition method' at the Gol-E-Gohar iron ore mine tosimulate the production blast seismograms based upon measurements of single-hole shot vibrations, carried out at a distance of $39 \mathrm{~m}$ from the blast. The production blast seismograms were then used as input to predict the particle velocity time histories in the mine wall using the three-dimensional discrete element method. In their research a "simulated annealing" search algorithm was employed to find the optimum values of unknown 
parameters. The final results of time histories of particle velocity showed a good agreementwith the measured time histories.

Hudaverdi [19] applied an innovative multivariate analysis procedure for the prediction of blast-induced ground vibration. He considered parameters related to ground vibration to perform multivariate analysis. He classified the blasts data into different groups of similarity using hierarchical cluster analysis and then analyzed and confirmed the membership groups by the discriminant analysis. In his investigation, a linear discriminant equation was developed for the estimation of blast induced ground vibration using regression analysis. The consequences of his study showed that using hierarchical cluster analysis could reduce the complexity of relationships between different parameters affecting ground vibration.

Dehghani and Ataee-Pour [20] carried out a study to develop a new formula based on Dimensional Analysis (DA) to predict PPV. They used sensitivity analysis between PPV and each input parameter of ANN model in order to find the most effective parameters in prediction of ground vibration and used them to apply DA technique. They concluded that vibration is a function of the most important parameters such as powder factor, charge per delay, and burden. The suggested mathematical model was compared with available conventional PPV predictors and found excellent blast results compared to conventional predictors.

Choi et al. [21] established a safe blast guideline that can secure the safety of open pit slopes against blast induced ground vibration in Pasir coal mine, Indonesia. In their study, first a general prediction equation for the ground vibration level was derived. After that, based on a numerical method, allowable ground vibration level was set. Finally, maximum charge weight per hole was determined based on the scaled distance.

Differential Evolution (DE) is a small and simple mathematical model of a large and naturally complex process of evolution [22]. Since its inception in 1995, DE has earned a reputation as a very effective global optimizer. While DE is not a panacea, its record of reliable and robust performance demands that it belongs in every scientist and engineer's "bag of tricks" [23].

Khandelwal and Saadat [24] proposed a new DA equation to predict the PPV and compare their findings with the various conventional predictors. They found very satisfactory results for the PPV prediction using DA equation compared to conventional predictors.

The present paper focuses on the application of DE Algorithm to predict blast induced ground vibration ofJayant opencast mine, NCL, India. DE algorithm and Multiple Linear Regression (MLR) analysis are conducted in order to evaluate the unknown coefficients of 
DA-based model. The blast vibration prediction of DA-based model optimized by DE and MLR is compared with commonly used vibration predictors.

\section{Conventional Predictors}

PPV is one of the most pervasive damage indicator criteria to assess detrimental effects of blasting on structures due to blasting. There is variety of empirical models suggested by different researchers for prediction of blast induced ground vibration. In this study, four widely used predictors are chosen in order to find the best approximation of PPV [4-7]. Table 1 illustrates the empirical models which are based on scaled distance laws. Scaled distance is defined as a hybrid variable of distance fromblastface to monitoring point and maximum amount of explosive charge used per delay. The unknown site constants of each empirical model can be approximated by the linear regression between PPV and scaled distance in a $\log -\log$ plane.

\section{Field Study Description}

The study was conducted at Jayant opencast mine of Northern Coalfields Limited (NCL), which is a subsidiary company of Coal India Limited. It is located at Singrauli, Distt. Sidhi (M.P.), India. The area of NCL lies geographically between latitudes of $24^{\circ} 0$ ' to 24 ${ }^{\circ} 12^{\prime}$ and longitudes $82^{\circ} 30^{\prime}$ to $82^{\circ} 45^{\prime}$ and belongs to Gondwana super group. This coalfield was discovered in year 1840 and mining was started some time before 1857 at Kota, Parari and Nawanagar localities in fragmented way. The geological succession is given in Table 2.

The total expansion of NCL containing rich coal horizons is about $2202 \mathrm{sq} \mathrm{km}$. The coalfield can be divided into two basins, viz. Moher sub-basin (312 sq km) and Singrauli Main basin (1890 sq km). Major part of the Moher sub-basin lies in the Sidhi district of Madhya Pradesh and a small part lies in the Sonebhadra district of Uttar Pradesh. Singrauli main basin lies in the western part of the coalfield. The present coal mining activities and explored blocks are concentrated in Moher sub-basin. It is divided into eleven mining blocks namely Kakri, Bina, Marrack, Khadia, Dhudhichua, Jayant, Nighahi, Amlohri, Moher, Gorbi and Jhingurdah [25].

In this coalfield, coal seams have been confined in Barakar and Raniganj formations. The boundary between Barakar and Raniganj formations is not clear here. The dips of the strata are gently varying between $2^{0}$ to $5^{0}$. The area contains no major fault even along the boundary of the basin. The characteristics of this field are that the fault is rare even along the boundary. In the eastern part of the coalfield, in Mohar area (Barakar formations), 
there are four coal productive seams designated as Kota seam, Turra seam, Lower Purewa and Upper Purewa seam [26].Turra and Purewa coal seams vary from 15 to $30 \mathrm{~m}$.

The Jingurda seam belongs to Raniganj formation is at places $138 \mathrm{~m}$ thick was reported to be thickest coal seam in India. The different types of sandstones are overlain and underlain the coal seams. These are coarse, medium and fine-grained sandstones, followed by carbonaceous shaly intercalation of sandy shales.

The overburden in this area is mostly medium to coarse-grained sandstones, carbonaceous shales and shaly sandstones. The mine uses large dragline $\left(24 \mathrm{~m}^{3}\right.$ bucket size and $96 \mathrm{~m}$ boom length) in $40 \mathrm{~m}$ benches with $311 \mathrm{~mm}$ diameter blast holes as well as excavators in other benches of 05-15 m height with 160 and $250 \mathrm{~mm}$ blast holes. Nonel and MS connectors are used for initiation. The inter-hole delay is generally kept as 17-25 ms, whereas, inter-row delay is two-four times the inter-hole delay.

\section{Data Sets}

\subsection{Data Collection}

The data sets used in this study are monitored from different vulnerable and strategic location in and around of Jayant open cast mine as per the International Society of Rock Mechanics (ISRM) standards [29]. Training and testing data sets are divided based on blast hole diameter in measure the versatility of DE model, instead of randomly dividing the data sets into various categories. Therefore, thirty-five blast vibration records were used for the training of differential evolution algorithm and multiple linear regression method. The same data sets are used for determination of site constants of conventional models. These data sets are recorded at a region where the blast hole diameter is $250 \mathrm{~mm}$. To understand the capability of DE in comparison with conventional models, twenty-one blast vibration records monitored at various locations are taken into account, where the blast hole diameter is 160 $\mathrm{mm}$. Tables 3 and 4 show the input and output parameters range, along with their mean and standard deviation, respectively. In Table 3, blast hole diameter is discarded because it remains constant for all training data sets $(250 \mathrm{~mm})$.

\subsection{Description of Blast Parameters and their Limitations}

As described in Table 3, different effective blast parameters are taken into account in

order to predict blast induced ground vibration. $H, B, S, \delta, W, D, \varphi$ and $\gamma$ are parameters used by a plethora of researchers for PPV prediction or blasting pattern design $[11,14,16,19$, and 
20]. In proposed predictor [24], $\rho$ andEare taken into account as indicators of geomechanical parameters. In the present study, $\rho$ is estimated by [30]

$$
\rho=\frac{\sigma_{c}}{\sigma_{t}}
$$

where $\sigma_{c}$ is the compressive strength and $\sigma_{t}$ is tensile strength of intact rock. One-hundred seventy-four rock samples were tested to determine $\rho, E$, Poisson's ratio and P-wave velocity as per ISRM standards [31-33]. Both $\rho$ and $E$ are regional parameters and there is an uncertainty regarding their impacts on blast induced ground vibration. It may be suggested that if $\rho$ and $E$ are regional parameters then they have minimum effect on prediction of the PPV.When variation of a parameter is significant, then it can be taken as a major input parameter. In this study, representative rock samples were collected from exposed rock mass of Singurali coal fields. Given the great variability in rock properties, even within the same rock type, it was consequently difficult, and not very meaningful, to cite specific values for specific rocks. However, in most of the discussion in rock mechanics problems, "rock" has been thought of as a homogeneous material that can be characterized by macroscopic parameters such as density, elastic moduli, etc., that are uniform over regions at least as large as a laboratory specimen. In most engineering calculations, it is convenient, and often practically necessary, to treat a rock mass as if it were homogeneous on the scale of a borehole, or tunnel, for example [34]. It is considered that the rock is homogeneous and isotropic so the effect of $\rho$ and $E$ as geomechanical parameters can be assumed to not be regional and as a consequence a specific value for $\rho$ and $E$ in each single data set can introduce their effect on blast induced ground vibration in any single shot.

\section{Differential Evolution Algorithm Theory and Background}

Differential Evolution (DE) algorithm is one of the evolutionary algorithms demonstrated to be an effective and robust method by applying in the optimization of some well-known non-linear, non-differentiable and non-convex functions [35-36]. Compared with other evolution algorithms, DE is easier to implement because it needs fewer parameters and exhibits fast convergence.The optimization procedures using DE are as follows [37]:

Step 1: Initial algorithm parameters. The major parameters of DE which remain constant along the optimization process, are the population size $N P$, scale factor $F$, crossover rate $C R$, and the maximum number of iterations GEN. 
Step 2: Population initialization. The algorithm starts by filling the primary array with NP vectors with randomly generated parameter values, $N P \times D$ matrix, $D$ is the dimension of the problem or the number of parameters. The generation method is

$$
X_{i j}=\text { low }[j]+(\text { high }[j]-\text { low }[j]) \text {.rand }
$$

in which $i=1,2, \ldots, N P, j=1,2, \ldots, D$. Rand is random number with a uniform probability distribution, and high $[j]$ and low $[j]$ are the upper bound and lower bound of the $j$ th column, respectively.

Step 3: Mutation. Each of these individual randomly-generated vectors $X_{i j}$ is considered sequentially for genetic operations. For each of the chosen vectors, three other vectors $X_{A}, X_{B}, X_{C}$ are randomly chosen from the remaining vectors of the primary array. The mutation operation uses these three randomly chosen vectors to produce a mutant vector

$$
X_{1}^{m}=X_{A}+F\left(X_{B}-X_{C}\right)
$$

where $X_{1}^{m}$ is the new mutant vector and $F$ is a scaling factor in the range of $0<F \leq 1.2$.

Step 4: Crossover. In order to produce offspring and increasing the diversity of the population crossover operation can be used. In this stage, a random integer number randint $(i)$ in the range of $[1, n]$ is generated. For each parameter $j=1, \ldots, n$, a random number randnum $(j)$ is generated in the space $[0,1]$. Then a new vector is created from the original $X_{i}$ parent and the mutant vector using the crossover criterion:

$$
X_{i, j}^{\prime}=\left\{\begin{array}{c}
X_{i, j}^{m} \text { if randnum } \leq C R \text { or } \operatorname{randint}(i)=j \\
X_{i, j} \text { if randnum }>C R \text { and } \operatorname{randint}(i) \neq j
\end{array}\right.
$$

where $C R$ is the crossover rate in the range of $[0,1]$

Step 5: Selection. At this stage if the randnum $\leq C R$ new trial vector will be obtained from the mutant vector $\left(X_{i, j}^{m}\right)$, otherwise the trail vector will be obtained from the parent vector.

The above mentioned steps restart until the stopping criterions are reached and consequently the final solution in the optimization process is obtained.

\section{Empirical Models}


There are many scientists conducting research to correlate structural damage with peak particle velocity. Significant declines in PPV value with distance from blast face to monitoring point makes it predictable with acceptable accuracy and allow restriction on blasting vibrations to be regulated either by means of mathematical expression [38]. This expression is mainly based on two major parameters, maximum charge per delay $(W)$ and distance from blast face to monitoring point $(D)$. An empirical model is a definition of PPV as a nonlinear function of $D$ and $W$. In this regard, site constants are the most influential parameters which are highly different from place to place. In this study, thirty-five blast data sets are used for evaluation of site constants. The site constants $K$ and $f$ are determined using four empirical models (Fig 1). The site constants of empirical models are given in Table 5. Then we can test each model and compare predicted PPV obtained by each model. As mentioned before, there are two different categories of data sets used in this study. The first datasets collected from a region where the diameter of blast holes is $250 \mathrm{~mm}$, used for evaluation of unknown site constants of empirical predictors. Then the testing procedure of each model has been carried out using data sets collected at another region with diameter of blast holes of $160 \mathrm{~mm}$.

After obtaining the site constants of conventional predictors, twenty-one new blast data sets are used in order to predict PPV. The correlation of determination (CoD) is varies from 0.04 to 0.62 for different empirical models. If we consider the sum of squares of the deviations of the observed y-values about $\bar{y}$ as $S S_{y y}=\sum\left(y_{i}-\bar{y}\right)^{2}$ and the sum of squares of the deviations of the $y$ values about the least-squares line as $\operatorname{SSE}=\sum\left(y_{i}-\hat{y}\right)^{2}$, the square of coefficient of correlation is called the coefficient of determination given by [39]:

$$
C o D=R^{2}=\frac{S S_{y y}-S S E}{S S_{y y}}
$$

The results revealed that Ambrasys-Hendron model has the highest $\mathrm{CoD}$ among four empirical models for the PPV prediction. The relationship between predicted PPV by different empirical models and monitored PPV are illustrated in Figs. 2-5.

\section{Dimensional Analysis Model}

Khandelwal and Saadat [24] proposed a model based on dimensional analysis technique to predict blast induced ground vibration. In DA-based model, the relationship between PPV and other effective parameters can be expressed as 


$$
\begin{aligned}
& \operatorname{Ln}\left(\sqrt{\frac{\gamma}{E}} P P V\right)=\lambda+\beta_{1} \operatorname{Ln}\left(\frac{\gamma D^{2} \delta}{W}\right)+\beta_{2} \operatorname{Ln}\left(\frac{\gamma D^{2} H}{W}\right) \\
& +\beta_{3} \operatorname{Ln}(\rho)+\beta_{4} \operatorname{Ln}\left(\frac{S}{\varphi}\right)+\beta_{5} \operatorname{Ln}\left(\frac{B}{\varphi}\right)
\end{aligned}
$$

where $\beta_{1}, \beta_{2}, \ldots, \beta_{5}$ are unknown coefficients. Equation (6) can be rewritten in a more simple form as follows:

$$
\left\{\begin{array}{l}
P P V=\left(\frac{D}{\sqrt{W}}\right)^{\alpha_{1}} \times \vartheta \\
\vartheta=\frac{e^{\lambda} \sqrt{E} \gamma^{\alpha_{2}}}{\varphi^{\alpha 3}}\left[\delta^{\beta_{1}} H^{\beta_{2}} \rho^{\beta_{3}} S^{\beta_{4}} B^{\beta_{5}}\right]
\end{array}\right.
$$

where

$$
\left\{\begin{array}{l}
\alpha_{1}=2\left(\beta_{1}+\beta_{2}\right) \\
\alpha_{2}=\beta_{1}+\beta_{2}-0.5 \\
\alpha_{3}=\beta_{4}+\beta_{5}
\end{array}\right.
$$

In this study, the unknown coefficients of DA-based model are evaluated using multiple linear regression and differential evolution algorithm.

\section{Multiple Linear Regression Analysis}

MLR analysis is employed to generate a mathematical relationship that describes variations on the blast induced ground vibration and different influential parameters. MLR is based on least squares, which means that the model is fit such that the sum of squares of differences of predicted and measured values are minimized. MLR is given by the following equation [39]:

$$
Y=\beta_{0}+\beta_{1} X_{1}+\ldots+\beta_{P} X_{P}+\xi
$$

where $Y$ is the predicted variable, $X_{i}(i=1,2,3, \ldots, P)$ are the predictors, $\beta_{o}$ is intercept of $Y, \beta_{i}(i=1,2,3, \ldots, P)$ is the coefficient on the $i$-th predictor and $\xi$ is the random error added to allow for derivation between the deterministic part of the model, $\beta_{0}+\beta_{1} X_{1}+\ldots+\beta_{P} X_{P}$, and the value of the dependent variable $Y$.

In order to employ MLR analysis the term $\operatorname{Ln}\left(\sqrt{\frac{\gamma}{E}} P P V\right)$ in eq. (6) is considered as dependent variable while the right side terms indicate the deterministic part. After analysis by 
conducting the same thirty-five blasting data sets used for evaluation of site constants of conventional predictors the following predictor is reached:

$$
\left\{\begin{array}{l}
P P V=\left(\frac{D}{\sqrt{W}}\right)^{-1.14} \times \vartheta \\
\vartheta=\frac{5064.45 \sqrt{E} \gamma^{-1.07}}{\varphi^{-0.07}}\left[\delta^{0.35} H^{-0.92} \rho^{0.56} S^{-0.62} B^{0.55}\right]
\end{array}\right.
$$

In the next step, twenty-one blast data sets measured in a bench with $160 \mathrm{~mm}$ bore hole diameter (the same data sets used for testing the conventional predictors) are taken into account for demonstration of the capability of this model. The fitting results between measured PPV and those of predicted by this model is illustrated in Fig 6.

\section{Blasting Pattern Design Optimization Using DE}

Based on eq. (7), the influence of suggested important parameters on blast induced ground vibration is investigated using the $\mathrm{DE}$ algorithm. In the DE procedure, the purpose is to optimize the following objective function:

$$
M S E=\frac{\sum_{i=1}^{N}\left(P P V_{O}-P P V_{T}\right)^{2}}{N}
$$

where $P P V_{O}$ and $P P V_{T}$ represent predicted and measure outputs, respectively, and $N$ is the total number of input and output data sets.MSEis known as mean square error.

The DE model is implemented in MATLAB software. In the DE algorithm, the number of unknowns is $n=6$ and the population size was taken as $N P=50$. The mutation factor, the crossover constant and the number of generations are 0.9, 0.7 and 1000, respectively. The reduction in MSE during DE implementation process is illustrated in Fig 7.

Using thirty-five blast data sets the unknown coefficients of eq. (7) has been evaluated. Now we have a new empirical formula which can be rewrite as follows:

$$
\left\{\begin{array}{l}
P P V=\left(\frac{D}{\sqrt{W}}\right)^{-1.18} \times \vartheta \\
\vartheta=\frac{1064.22 \sqrt{E} \gamma^{-1.09}}{\varphi^{-0.36}}\left[\delta^{-0.51} H^{-0.08} \rho^{0.48} S^{-2.07} B^{1.71}\right]
\end{array}\right.
$$

In order to test the results obtained by the DE algorithm, the same blast data sets used for prediction of PPV based on empirical models are taken into account. Testing results revealed 
that the new empirical formula demonstrates the capability of prediction of blast induced ground vibration with the highest $\mathrm{CoD}$ and the least MAE in comparison with empirical models. The results are illustrated in Fig 8.

\section{Results and Discussion}

As a results of DE algorithm and MLR analysis, a prediction model proposed by dimensional analysis technique were optimized. The proposed formulas provide the opportunity to predict blast induced ground vibration using wide range of effective blast design parameters. The results obtained by $\mathrm{DE}$ model are very close to actual site measurement values in comparison with conventional predictors and MLR model. The comparison graph is illustrated in Fig 9. The underestimation or overestimation in all models is inevitable, but this is not the final decision criteria for choosing the best model for PPV prediction. The mean absolute error (MAE) and CoDare two statistical descriptors indicating how close are predicted PPV values to actual measured PPV. According to Table 6, the proposed DA-based model optimized by DE has the highest $\mathrm{CoD}$ and the least MAE in comparison with conventional predictors. The MAE is given by

$$
M A E=\frac{1}{n} \sum_{i=1}^{n}\left|P P V_{o}-P P V_{T}\right|=\frac{1}{n} \sum_{i=1}^{n}\left|\eta_{i}\right|
$$

As the name suggests MAE is an average of the absolute errors $\eta_{i}=P P V_{o}-P P V_{T}$. In the previous study [24] the advantages and disadvantages of the DA model are described. In the present study, an attempt has been made to predict the blast induced ground vibration of Jayant opencast coal mine using new mathematical model. In the previous study [24], MLR was used to determine the unknown coefficient of formula and the efficiency of that analysis was concluded in comparison with conventional models. In that study, the versatility of proposed model for the PPV prediction was obtained using MLR analysis trained by 105 blast data sets and tested by twelve new blast data sets.

In the present study, MLR and DE both are used to find the best possible solution for the prediction of blast induced ground vibration using an equation obtained from dimensional analysis technique. However, results of the MLR model to predict the PPV were closer to the measured PPV values, but it showed error in PPV prediction for few data sets. To overcome

this, a DE approach is conducted to evaluate the unknown coefficients of the DA-based equation with higher accuracy and obtaining more satisfactory results in testing procedure. 
As it illustrated in Fig 9, the results of DE model is very close to measured PPV in comparison with the prediction results of MLR model.

The results of DE-based suggested formula are more promising and satisfactory than those of obtained by MLR-based approach both in terms of CoD and MAE values. The capability of DE-based proposed model is tested in a region where blast holes diameter were $160 \mathrm{~mm}$.

It is a common practice among researchers to take $90 \%$ data to determine site constants and remaining $10 \%$ data to verify the results. In this study, the purpose is to predict blast induced ground vibration in a bench where blast hole diameter is $160 \mathrm{~mm}$ and comparing the capability of different PPV predictors in that particular region. The available number of blasting data sets in that bench is twenty-one. For this reason, instead of considering three or four data sets the whole available data sets are taken into account for testing the models.

The considerable merit of dimensional analysis technique can be examined in prediction of blast induced ground vibration. The first reason is that it can introduce the relationships between various blasting parameters in a tangible mathematical result. The next reason is that there are an infinite variety of correct solutions because of the partial (incomplete) tendency of DA technique [24].

In new model one of the major parameters is the scaled distance of USBM model considered in the procedure of DA technique. The purpose behind proposing DA-based formula is enhancement of USBM model by taking into account other influential parameters used by various researchers for PPV prediction. It worth introducing that the design capability of proposed model is mainly depended on the influence of square-root scaled distance. Among conventional predictors, the Ambraysis-Hendron and USBM models demonstrate better capability. PPV in these predictors is defined as a function of $\left[\frac{D}{W^{\psi}}\right]^{-f}$ where $\psi$ is $1 / 2$ for USBM, and $1 / 3$ for Ambraeys-Hendron.

A very good agreement between predicted and monitored PPV values is obtained using DE for optimization of DA model. DE can be implemented simply as an optimizer program that controls the non-linear relationships between blasting parameters. For highly complex analysis DE tend to be time consuming, however for more simple problems without rigorous procedures the designer can be sure that his model is very efficient and complete.On the other hand, it is highly unlikely to obtain a model that would have the capability of PPV prediction with $100 \%$ accuracy. This can be concluded by achieving some values which are significantly 
overestimated or underestimated in testing procedure of all models. This study is not about finding a remedy for prediction of ground vibration with the most possible accuracy, but the ultimate goal of the authors is to suggest a model that has the highest accuracy and the most versatility among other available conventional predictors for blasting design pattern in Jayan opencast coal mine.

\section{Conclusions}

The purpose of this study is to develop a new model to predict Peak Particle Velocity (PPV) at Jayant opencast coal mine based on various blasting design parameters and geomechanical data. A model proposed based on dimensional analysis (DA) technique was used that takes into account 10 different effective parameters for prediction of PPV.

The differential evolution (DE) algorithm and multiple linear regressions (MLR) method were employed to find the best descriptor model for predicting blast induced ground vibration. Thirty-five blast data sets monitored at a bench where blast hole diameter is 250 $\mathrm{mm}$ were considered to train DA-based model using DE algorithm and MLR method. After obtaining the unknown coefficients of DA-based formula, twenty-one blast data sets monitored at another bench in the Jayant opencast coal mine where blast hole diameter is 160 $\mathrm{mm}$ were taken into account for testing the capability of given formulas. The results were compared based on two fitting parameter namely coefficient of determination (CoD or RSquare) and mean absolute error (MAE). From successful prediction results of DE model, it is confidently concluded that DE algorithm can be applied to find the non-linear relationships of different effective parameters used in DA-based formula.

In order to understand the efficiency of DE model the same data sets used in training and test processes were applied to four widely used conventional PPV predictors. Square and cubic root scaled distance predictors (USBM and Ambraseys-Hendron) are the best among other empirical models. One of the major parameters used in DA procedure is square root scaled distance used in USBM model.The enhancement of USBM formula by considering various effective parameters and the implementation of DE for optimization of DA-based formula shows a better performance of PPV prediction. Although the optimized DA-based model cannot be considered as a more universal and reliable PPV predictor than empirical models, it can be regarded as a common base and versatile model for prediction of PPV at Jayant opencast coal mine. 


\section{References}

[1] Liang Q, An Y, Zhao L, Li D, Yan L. Comparative study on calculation methods of blasting vibration velocity. Rock Mech Rock Eng 2011; 44:93-101.

[2] Monjezi M, Ahmadi M, Sheikhan M, Bahrami M, Salimi AR. Predicting blast-induced ground vibration using various types of neural networks. Soil Dyn Earthquake Eng 2010; 30:1233-1236.

[3] Shi XZ, Chen SHR. Delay time optimization in blasting operations for mitigating the vibration-effects on final pit walls' stability. Soil Dyn Earthquake Eng 2011; 31:1154-1158.

[4] Duvall WI, Fogelson DE. Review of criteria for estimating damage to residences from blasting vibrations. USBM-I; 1962.5968.

[5] Langefors U, Kihlström B. The modern technique of rock blasting. New York: Wiley; 1963.

[6] Ambraseys NN, Hendron AJ. Dynamic behaviour of rock masses. In: Stagg KG, Zienkiewicz OC (eds) Rock mechanics in engineering practices. London: Wiley; 1968. pp 203-207.

[7] Bureau of Indian Standards (BIS) Criteria for safety and design of structures subjected to underground blast. ISI Bull 1973;IS-6922.

[8] Iphar M, Yavuz M, Ak H. Prediction of ground vibrations resulting from the blasting operations in an open-pit mine by adaptive neuro-fuzzy inference system. Environ Geol 2008; 56:97-107.

[9] Khandelwal M, Singh T.N. Evaluation of blast-induced ground vibration predictors. Soil Dyn Earthquake Eng 2007; 27: 116-125

[10] Khandelwal M, Singh TN. Prediction of blast-induced ground vibration using artificial neural network. Int J Rock Mech Min Sci 2009;46: 1214-1222.

[11] Monjezi M, Amin Khoshalan H, Yazdani Varjani A. Optimization of open pit blast parameters using genetic algorithm. Int J Rock Mech Min Sci 2011; 48: 864-869. 
[12] Mohamdnejad M, Gholami R, Ataei M. Comparison of intelligence science techniques and empirical methods for prediction of blasting vibrations. Tunnell Undergr Space Technol 2012;28: 238-244.

[13] Lapčević R, Kostić S, Pantović R, Vasović N. Prediction of blast-induced ground motion in a copper mine. Int J Rock Mech Min Sci 2014;69: 19-25.

[14] Khandelwal M. Evaluation and prediction of blast-induced ground vibration using support vector machine. Int J Rock Mech Min Sci 2010; 47: 509-516.

[15] Álvarez-Vigil AE, Gonzàlez-Nicieza C, LópezGayarre F, Álvarez-Fernández MI. Predicting blasting propagation velocity and vibration frequency using artificial neural networks. Int J Rock Mech Min Sci 2012; 55:108-116

[16] Verma AK, Singh TN. Comparative study of cognitive systems for ground vibration measurements. Neural Comput Applic 2013; 22: 341-350.

[17] Ghasemi E, Mehmet S, Ataei M. Development of an empirical model for predicting the effects of controllable blasting parameters on flyrock distance in surface mines. Int J Rock Mech Min Sci 2012;52: 163-170.

[18] Babanouri N, Mansouri H, KarimiNasab S, Bahaadini M. A coupled method to study blast wave propagation in fractured rock masses and estimate unknown properties. Comput Geotech 2013; 49: 134-142.

[19] Hudaverdi T. Application of multivariate analysis for prediction of blast-induced ground vibrations. Soil Dyn Earthquake Eng 2012; 43: 300-308.

[20] Dehghani H, Ataee-pour M. Development of a model to predict peak particle velocity in a blasting operation. Int J Rock Mech Min Sci 2011; 48: 51-58.

[21] Choi B, Ryu C, Deb D, Jung Y, Jeong J. Case study of establishing a safe blasting criterion for the pit slopes of an open-pit coal mine. Int J Rock Mech Min Sci 2013;57: 1-10.

[22] Feoktistov V. Differential Evolution in Search of Solutions. New York: Springer; 2006.

[23] Price KV, Storn RM, Lampinen JA. Differential evolution approach to global optimization. Berlin: Springer; 2005. 
[24] Khandelwal M, Saadat M. A dimensional analysis approach to study blast-induced ground vibration. Rock Mech Rock Eng 2015; 48:727-735.

[25] Singh VK. Northern Coalfields Ltd: Surging ahead with time. J Mines Metals Fuels $2004 ; 51$.

[26] Chandra D, Singh RM, Singh MP. Text book of coal. Varanasi: Tara Book Agency; 2000 .

[27] Laskar B, Mukherjee KN, Dutta KK. Geology and coal resources of the eastern part of Singrauli coal fields, U.P. and M.P. Geological Survey of India 1977; 108(2):170-181.

[28] Raja Rao CS, Coal fields of India, coal resources of Madhya Pradesh and Jammu and Kashmir. Geol Surv India Bull Ser A 1983; 63(3):240

[29] Dowding CH. Suggested method for blast vibration monitoring. Int J Rock Mech Min Sci Geomech Abstr 1992; 29:143-156.

[30] Hino K. Theory and practice of blasting. Tokyo: Nippon Kayaku Co; 1959.

[31] ISRM. Suggested methods for determining tensile strength of rock materials. Int J Rock Mech Min Sci Geomech Abstr 1978;15:124.

[32] ISRM. Suggested methods for determining the uniaxial compressive strength and deformability of rock materials. Int J Rock Mech Min Sci Geomech Abstr 1979;16:135-40.

[33] ISRM. Suggested method for determining sound velocity. Int J Rock Mech Min Sci Geomech Abstr 1978;15:A100.

[34] Jaeger JC, Cook NGW, Zimmerman RW. Fundamentals of Rock Mechanics, $4^{\text {th }}$ edition. Malden, Mass: Blackwell; 2007. pp 281, 353.

[35] Wang L, Dun CX, Bi WJ, Zeng YR. An effective and efficient differential evolution algorithm for the integrated stochastic joint replenishment and delivery model. KnowledgeBased Systems 2012; 36 104-114.

[36] Storn, R., Price, K. Differential evolution - a simple and efficient heuristic for global optimization over continuous spaces. J Global Optim 1997; 11: 341-359. 
[37] R. Storn, K. Price, Differential evolution - a simple and efficient adaptive scheme for global optimization over continuous spaces, Technical Report 1995, TR-95.012, ICSI.

[38] Nateghi R. Prediction of ground vibration level induced by blasting at different rock units. Int J Rock Mech Min Sci 2011;48: 899-908.

[39] Scheaffer R, Mulekar M, McClave J. Probability and statistics for engineers, 5th edn. Boston: Brooks/Cole; 2011. pp 88, 598. 


\section{Tables}

Table 1. Conventional predictors used in this study

Table 2. General geological succession of the Singrauli coalfields [27]

Table 3. Input parameters with range, mean and standard deviation

Table 4. Output parameter with range, mean and standard deviation

Table 5. Site constants determined for conventional predictors

Table 6. CoD and MAE of different predictors 


\section{Figures}

Fig. 1. Log-Log plots between PPV and scaled distance for various conventional models; $D$ is the distance from blast face to monitoring point $(\mathrm{m}), W$ is the maximum charge per delay $(\mathrm{kg})$.

Fig. 2. Relationship between measured and predicted PPV by Ambraseys-Hendron

Fig. 3. Relationship between measured and predicted PPV by BIS

Fig. 4. Relationship between measured and predicted PPV by Langeforse-Kihlstrom

Fig. 5. Relationship between measured and predicted PPV by USBM

Fig. 6. Relationship between measured and predicted PPV by MLR

Fig. 7. MSE vs Generation during DE implementation process

Fig. 8. Relationship between measured and predicted PPV by DE

Fig. 9. Comparison grapgh using different predictors 
Table 1. Conventional predictors used in this study

\begin{tabular}{cc}
\hline Name & Equation \\
\hline $\begin{array}{c}\text { United States Bureau of Mines } \\
\text { (USBM) } \\
\text { (Duvall and Fogelson, 1962) }\end{array}$ & $P P V=K\left(\frac{D}{\sqrt{W}}\right)^{-f}$ \\
\hline $\begin{array}{c}\text { Langefors-Kihlstrom } \\
\text { (Langefors and Kihlstrom, 1963) }\end{array}$ & $P P V=K\left(\sqrt{\frac{W}{D^{2 / 3}}}\right)^{f}$ \\
\hline $\begin{array}{c}\text { Ambraseys-Hendron } \\
\text { (Ambraseys and Hendron, 1968) }\end{array}$ & $P P V=K\left(\frac{D}{W^{1 / 3}}\right)^{-f}$ \\
\hline $\begin{array}{c}\text { Bureau of Indian Standard (BIS) } \\
\text { (Indian Standard Institute, 1973) }\end{array}$ & $P P V=K\left(\frac{W}{D^{2 / 3}}\right)^{f}$ \\
\hline
\end{tabular}

PPV is $\overline{\text { Peak Particle Velocity }(\mathrm{mm} / \mathrm{s}), D \text { is the distance from blast face to monitoring point }(\mathrm{m}), W}$ is the maximum charge per delay $(\mathrm{kg})$, and $K \& f$ are the site constants 
Table 2. General geological succession of the Singrauli coalfields [27]

\begin{tabular}{|c|c|c|c|}
\hline Age & Group & Formation & Lithology \\
\hline Recent & & & Alluvium \\
\hline Upper Permian & Damuda & Raniganj & $\begin{array}{l}\text { Fine grained sandstone, shale, carbonaceous shale } \\
\text { and white to grey clays with thick coal seams. }\end{array}$ \\
\hline Middle Permian & & $\begin{array}{l}\text { Barren } \\
\text { Measure }\end{array}$ & $\begin{array}{l}\text { Very course grained to ferruginous sandstone and } \\
\text { shale with red-green clays. }\end{array}$ \\
\hline Lower Permian & & Barakar & $\begin{array}{l}\text { Medium to coarse grained sandstone, shale carb. } \\
\text { Shale, white to pink clays and coal seams. }\end{array}$ \\
\hline $\begin{array}{l}\text { Upper } \\
\text { Carboniferous }\end{array}$ & & Talchir & $\begin{array}{l}\text { Tillite, sandstone, needle shale, siltstone, boulder } \\
\text { conglomerate. }\end{array}$ \\
\hline Precambrian & . & $\begin{array}{l}\text { Unconformity } \\
\text { Bijawar }\end{array}$ & Phyllite, quartzite, schists and gneisses. \\
\hline
\end{tabular}


Table 3. Input parameters with range, mean and standard deviation

\begin{tabular}{lllllll}
\hline S. no & Input parameter & Symbol & Min & Max & Mean & SD \\
\hline 1 & Hole depth (m) & $H$ & 5 & 35 & 14.5 & 8.63 \\
2 & Burden (m) & $B$ & 2 & 8 & 6 & 1.59 \\
3 & Spacing (m) & $S$ & 3 & 9 & 7 & 1.93 \\
4 & Charge length (m) & $\delta$ & 1 & 28 & 8 & 7.99 \\
5 & Max charge per delay & $W$ & 50 & 5600 & 2400 & 2044.79 \\
6 & $(\mathrm{~kg})$ & & & & & \\
7 & Distance (m) & $D$ & 35 & 3000 & 475 & 833.64 \\
8 & Young's Modulus (Gpa) & $E$ & 5.19 & 9.67 & 7.38 & 1.23 \\
9 & Blastability index & $\rho$ & 0.18 & 0.35 & 0.25 & 0.046 \\
\hline
\end{tabular}


Table 4. Output parameter with range, mean and standard deviation

\begin{tabular}{llllll}
\hline S. no & $\begin{array}{l}\text { Output } \\
\text { parameter }\end{array}$ & Min & Max & Mean & SD \\
\hline 1 & $\begin{array}{l}\text { PPV } \\
(\mathrm{mm} / \mathrm{s})\end{array}$ & 0.31 & 72.02 & 7.31 & 14.58 \\
\hline
\end{tabular}


Table 5. Site constants determined for conventional predictors

\begin{tabular}{lcc}
\hline Empirical Model & \multicolumn{2}{c}{ Site Constant Values } \\
\cline { 2 - 3 } & $\mathrm{K}$ & $\mathrm{B}$ \\
\hline USBM & 17.82 & -0.26 \\
Longefors-Kihlstrom & 13.76 & -0.43 \\
Ambraseys-Hendron & 37.64 & -0.37 \\
BIS & 13.76 & -0.21 \\
\hline
\end{tabular}


Table 6. CoD and MAE of different predictors

\begin{tabular}{lcc}
\hline Model & CoD & MAE \\
\hline Ambraseys-Hendron & 0.62 & 2.94 \\
USBM & 0.36 & 2.56 \\
Longefors-Kihlström & 0.04 & 5.31 \\
BIS & 0.04 & 5.33 \\
MLR & 0.77 & 2.83 \\
DE & 0.83 & 1.25 \\
\hline
\end{tabular}



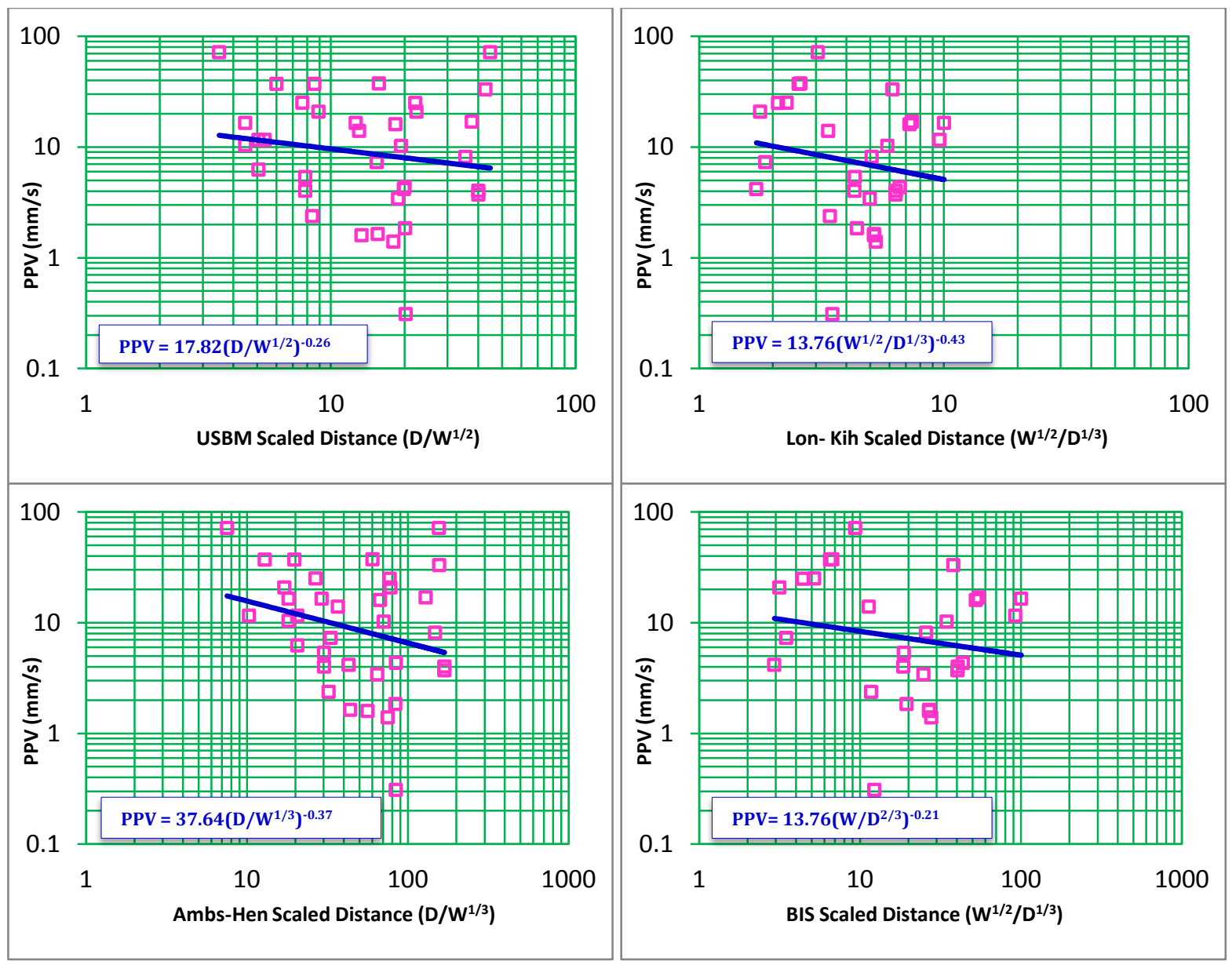

Fig 1. Log-Log plots between PPV and scaled distance for various conventional models ( $\mathrm{D}$ is the distance from blast face to monitoring point $(\mathrm{m}), \mathrm{W}$ is the maximum charge per delay $(\mathrm{kg})$ ) 


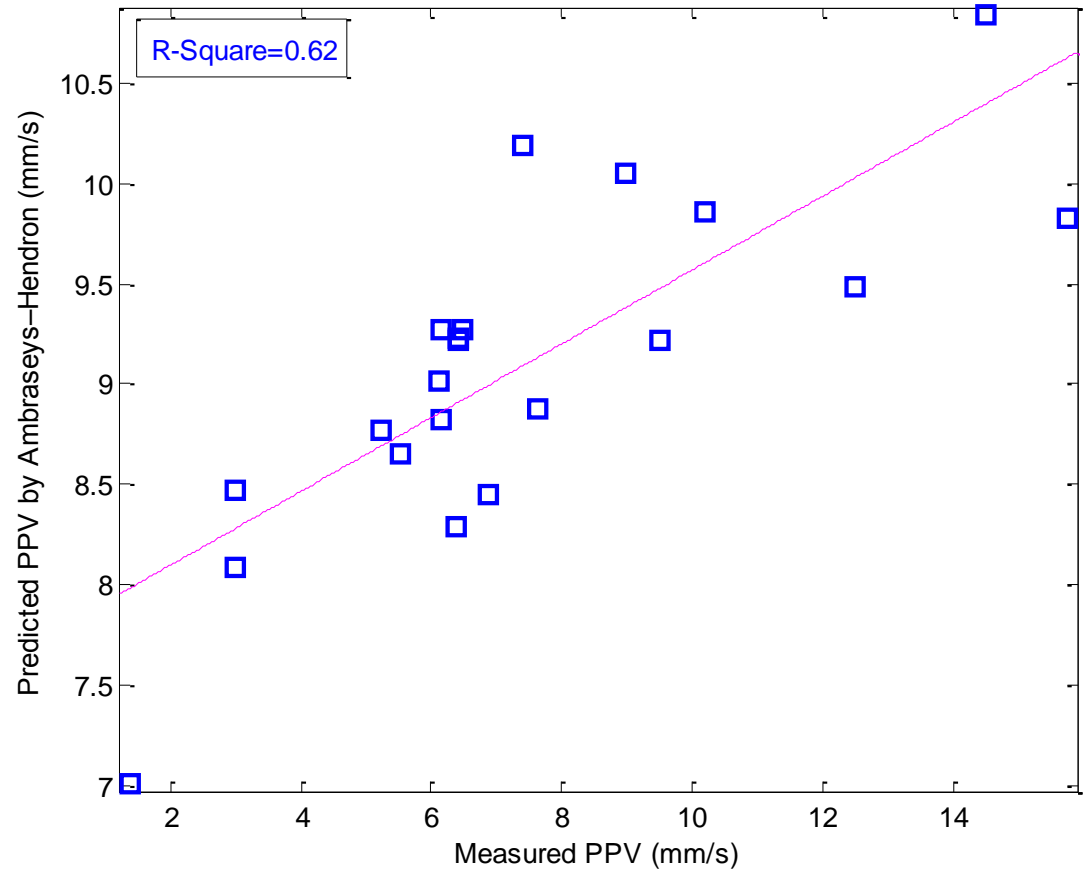

Fig 2. Relationship between measured and predicted PPV by Ambraseys-Hendron 


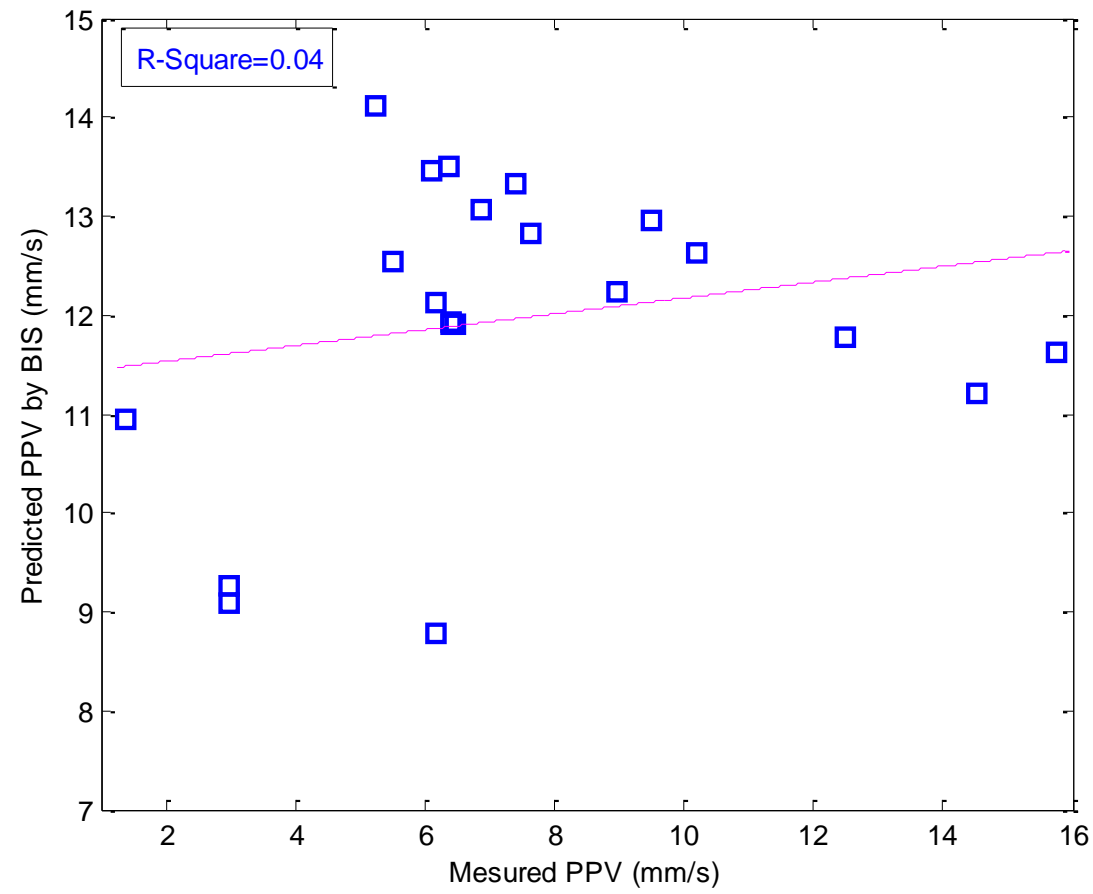

Fig 3. Relationship between measured and predicted PPV by BIS 


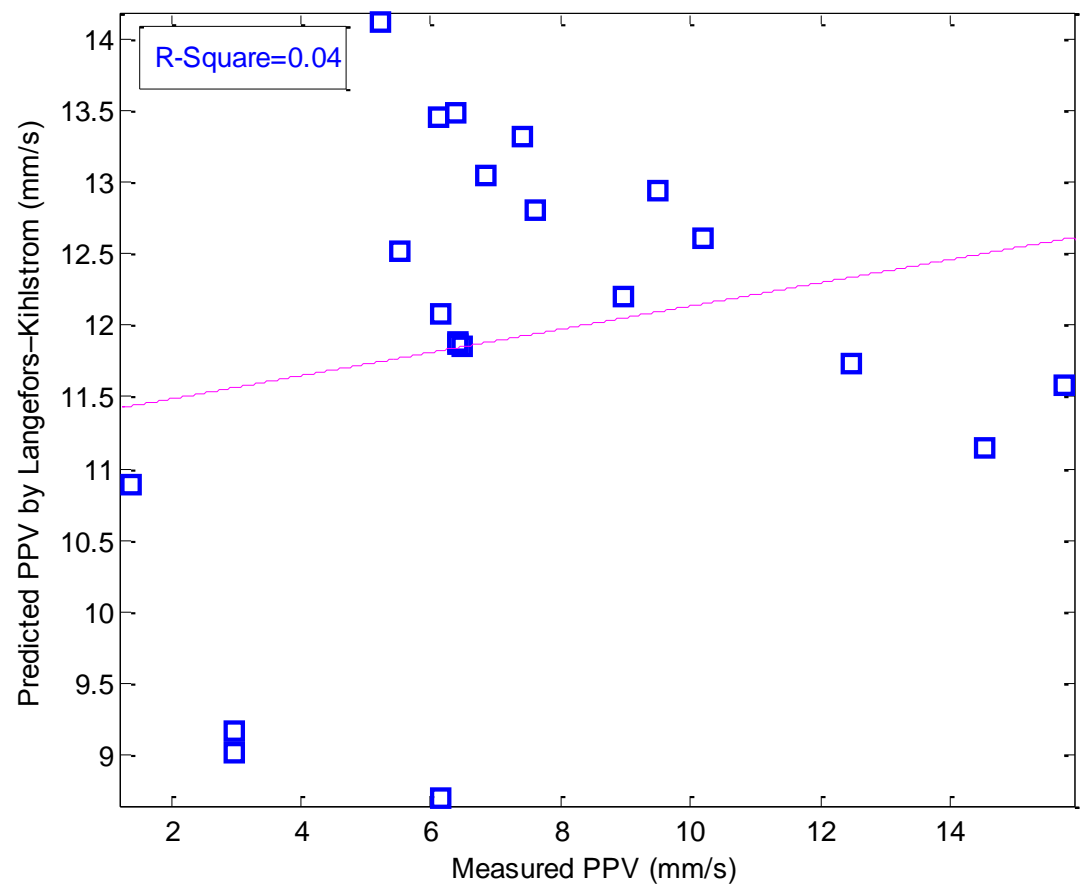

Fig 4. Relationship between measured and predicted PPV by Langeforse-Kihlstrom 


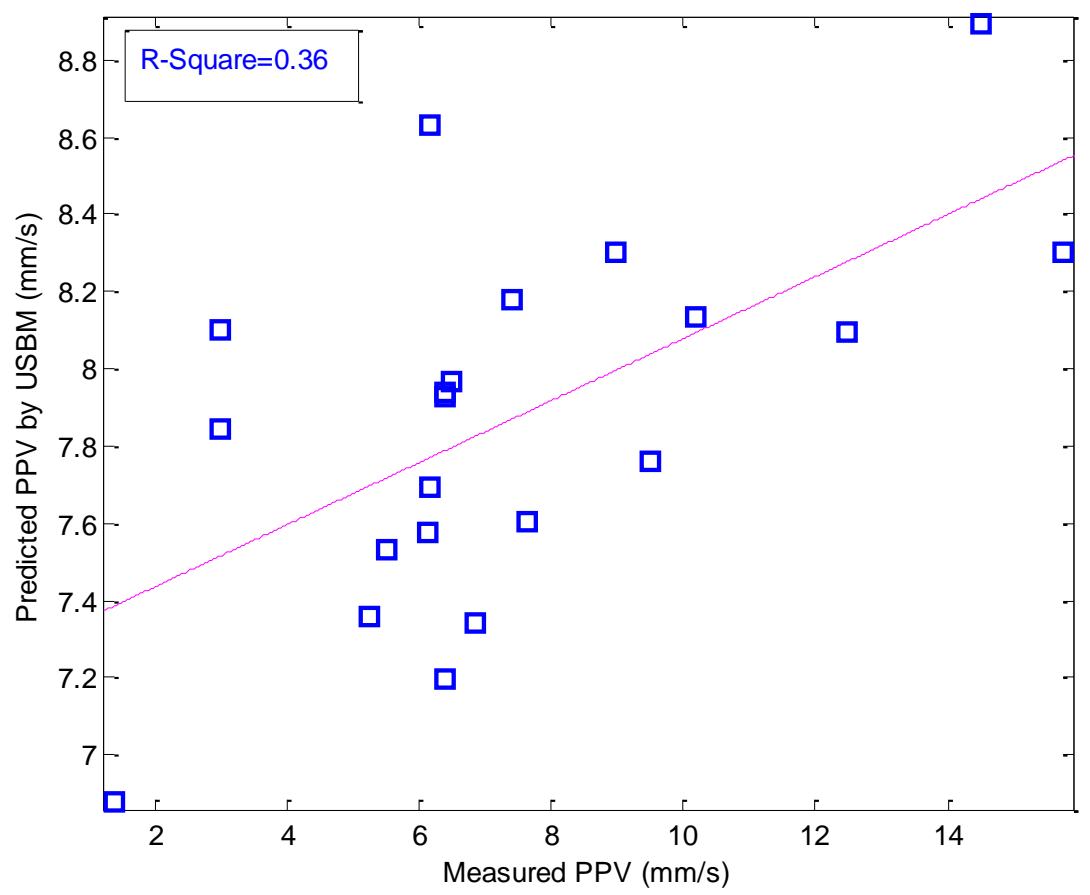

Fig 5. Relationship between measured and predicted PPV by USBM 


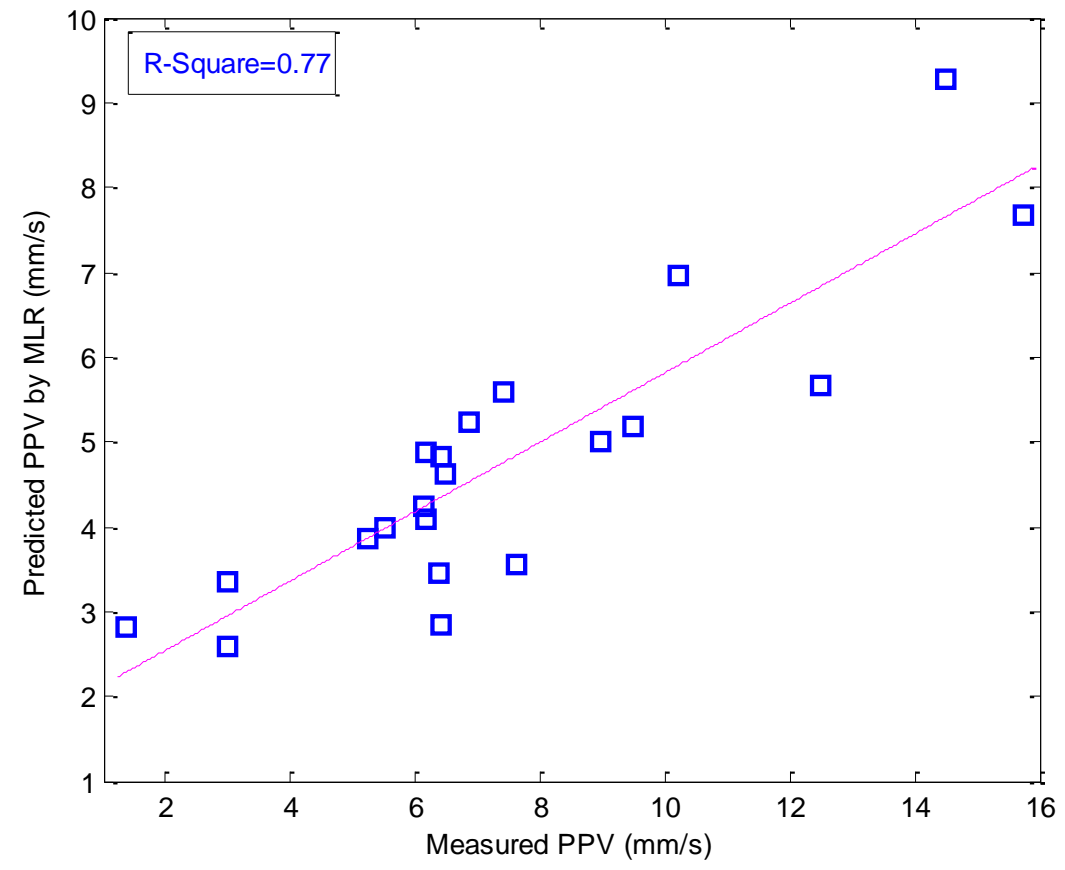

Fig 6. Relationship between measured and predicted PPV by MLR 


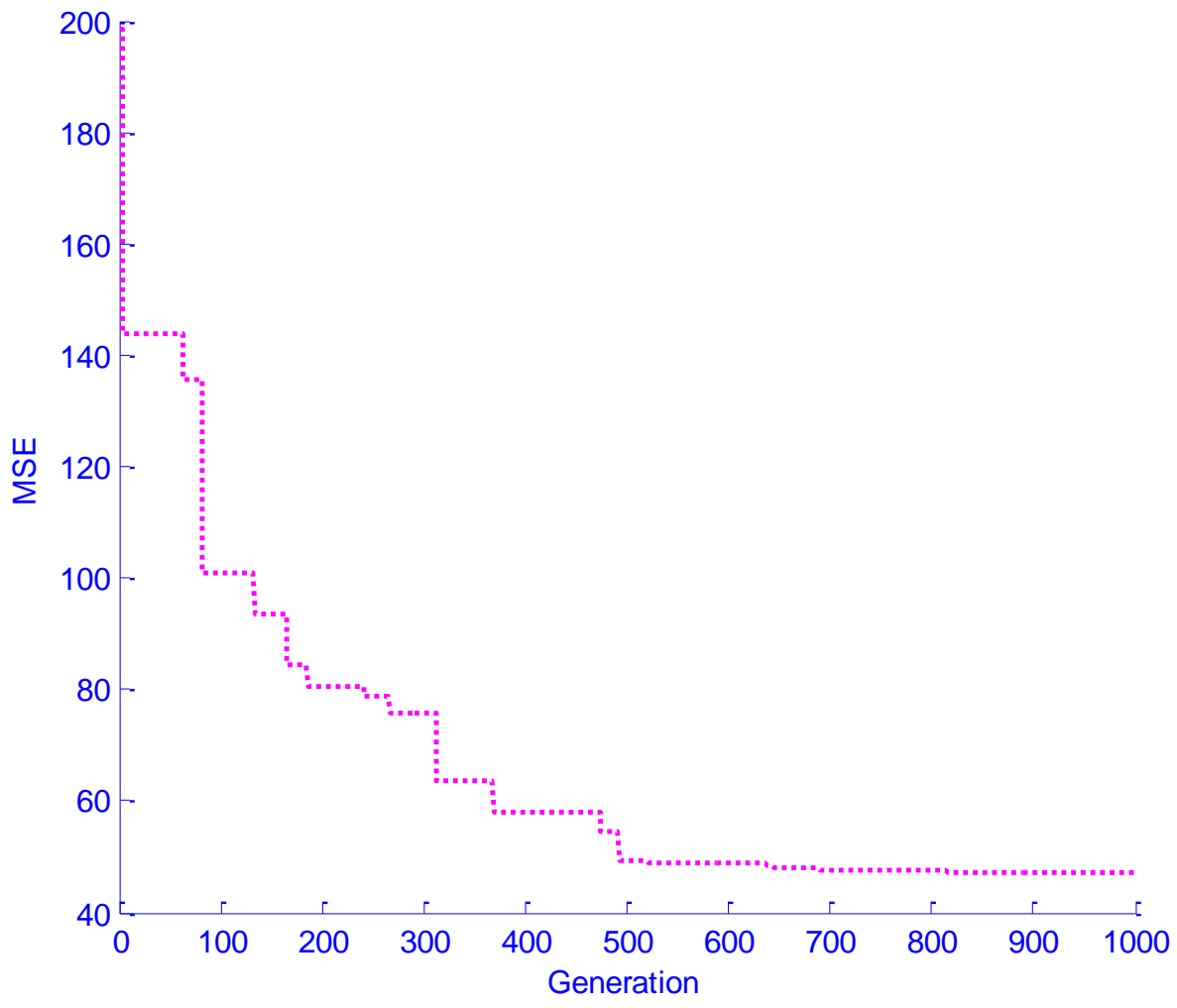

Fig 7. MSE vs Generation during DE implementation process 


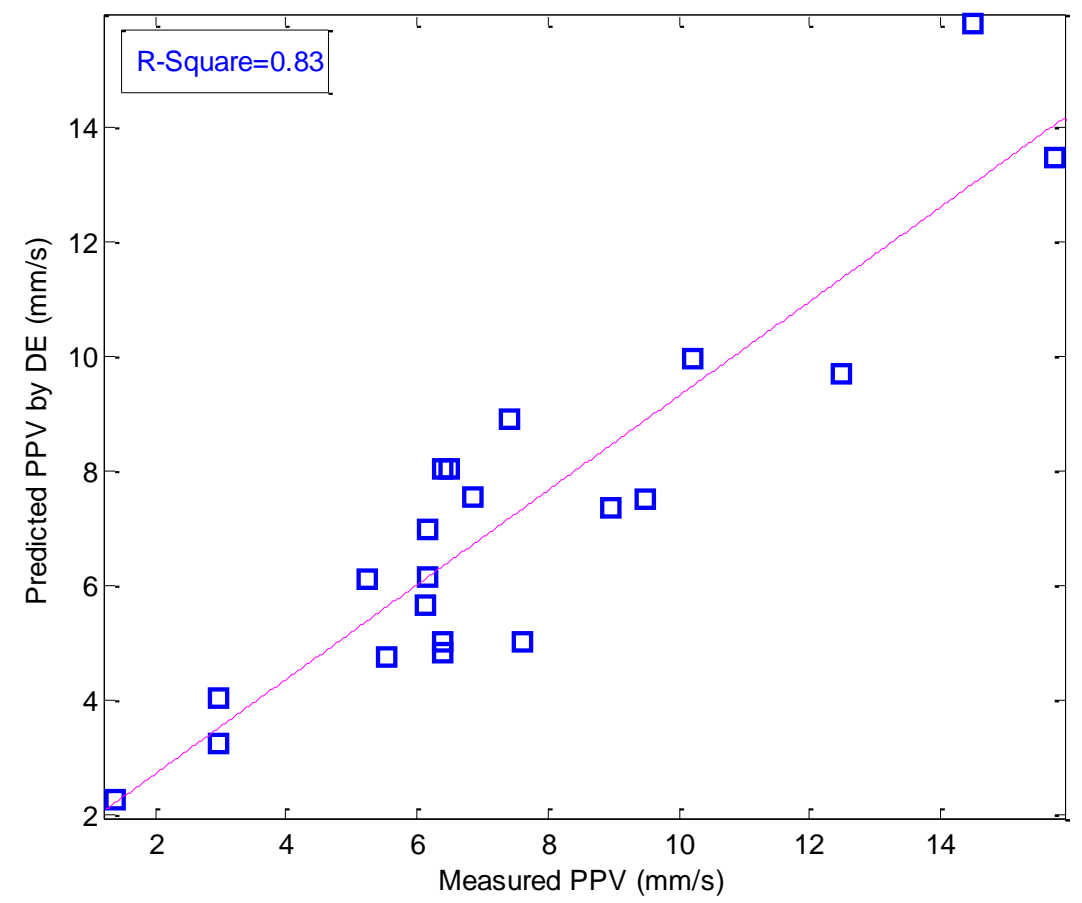

Fig 8. Relationship between measured and predicted PPV by DE 


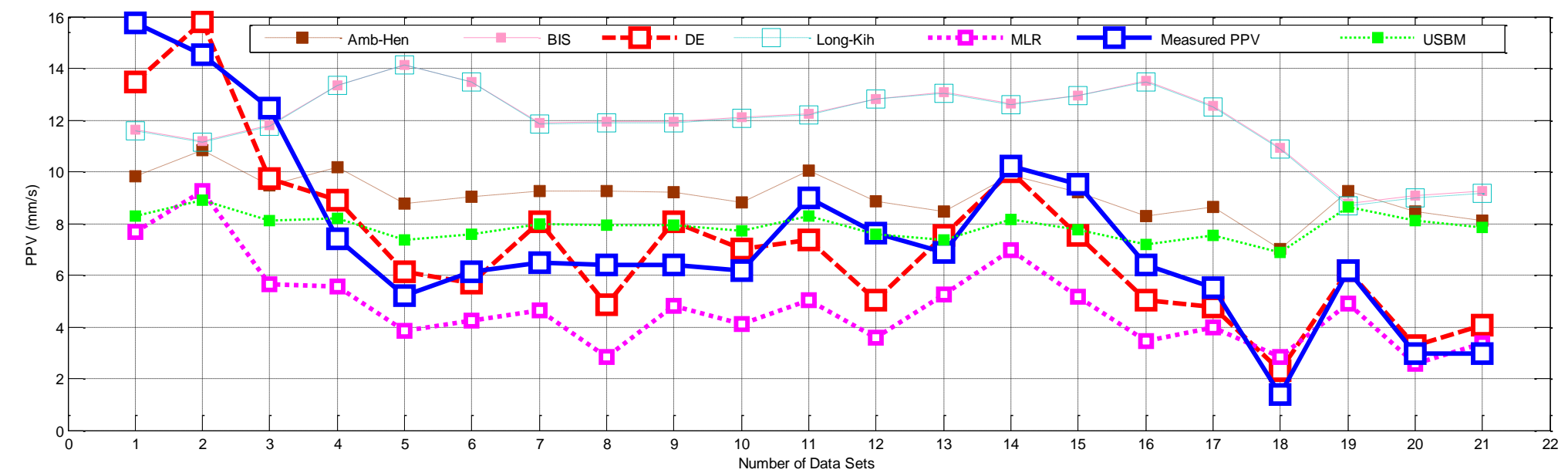

Fig 9. Comparison graph using different predictors 